\title{
Tyrosine phosphorylation in the human duodenum
}

\author{
D Kelleher, A Murphy, O Sheils, A Long, J McDevitt
}

\begin{abstract}
Many growth factor receptors including the epidermal growth factor receptor function through tyrosine kinase activity. The aim of this study was to examine the constitutive level of tyrosine phosphorylation in the normal duodenum and in the hyperproliferative coeliac duodenum. A flow cytometric assay was devised using monoclonal antibody to phosphorylated (but not native) tyrosine residues to determine the levels of tyrosine phosphorylation in both CD3 positive intraepithelial lymphocytes and CD3 negative epithelial cells obtained by EDTA treatment of endoscopically obtained duodenal biopsy specimens. In addition, immunohistochemistry was performed on 18 formalin fixed coeliac duodenal biopsy specimens and eight control specimens. Tyrosine phosphorylation could be detected by flow cytometry on duodenal enterocytes and this expression was up regulated by pretreatment with epidermal growth factor. Tyrosine phosphorylation decreased with progression from the villus to the crypt, however, and was virtually undetectable on crypt enterocytes. Immunohistochemistry of the coeliac duodenum showed virtually absent tyrosine phosphorylation in the crypt. Increased tyrosine phosphorylation was detected in the infiltrating $T$ cells. In conclusion, tyrosine phosphorylation in the duodenum is confined to the non-proliferative villous epithelium and is virtually undetectable in the proliferative crypt compartment. These findings suggest that tyrosine kinase activity is not a significant factor in the regulation of crypt cell proliferation in the human duodenum either in normal subjects or in coeliac disease patients. (Gut 1995; 36: 34-38)
\end{abstract}

Keywords: tyrosine phosphorylation, duodenum.

A large range of polypeptides, including growth factors such as epithelial growth factors, differentiation factors, and hormones, mediate their biological activity by binding to and activating cell surface receptors with intrinsic tyrosine kinase activity. ${ }^{12}$ Activation of these tyrosine kinase enzymes is usually mediated by receptor oligomerisation with subsequent conformational changes in the catalytic domain, which is normally intracellular. ${ }^{3}$ The epidermal growth factor receptor (EGFR) is a well characterised receptor with intrinsic tyrosine kinase activity and significant homology to the erb b onco- gene. ${ }^{4}$ It has been reported that epidermal growth factor (EGF) has a significant role in growth promotion of epithelial cells in vitro. In the rat, EGF, either directly or indirectly, is a potent stimulator of intestinal epithelial cell proliferation. ${ }^{56}$ It has also been shown that EGF may have a proliferative effect in vivo in the human neonatal intestine. ${ }^{7}$ It is notable, however, that when EGF is given intralumenally the results on epithelial proliferation are variable. ${ }^{89}$ As one of the important sites of release of EGF in the human intestine is through central channels at the villous tip, ${ }^{10}$ this might suggest that the effects of intralumenal EGF in the human intestine are limited or are not related to proliferation.

Antibodies to phosphorylated tyrosine residues now permit the assay of tyrosine kinase activity within a cellular system. We have developed a system using monoclonal antibody $1 G 2^{11}$ to phosphotyrosine residues to study the constitutive values of tyrosine phosphorylation and hence inferentially tyrosine kinase activity in both epithelial cells and $\mathrm{T}$ cells by two colour flow cytometry. This monoclonal antibody has previously been used to identify surface and cytoplasmic proteins phosphorylated on tyrosine in response to colony stimulating factor $1^{12}$ and interleukin 2.13 Flow cytometric studies have shown a linear correlation between values of tyrosine phosphorylation on phosphoamino analysis and results obtained by flow cytometry. ${ }^{14}$ We have used this technique to examine levels of tyrosine phosphorylation in the human duodenum. In addition, we took patients with coeliac disease as a model for increased crypt cell proliferation and performed immunohistochemistry on duodenal biopsy specimens obtained from both normal subjects and from coeliac disease patients.

\section{Methods}

PATIENTS

Duodenal biopsy specimens were obtained endoscopically from the second stage of the duodenum from patients giving informed consent. Patients were receiving endoscopy for dyspeptic symptoms and were all found to have a normal small intestine. Archival formalin fixed material was used for the study of in situ immunohistochemistry. Archival material was obtained from 18 patients with coeliac disease and six normal controls.

FLOW CYTOMETRIC ANALYSIS OF ENTEROCYTE PHOSPHOTYROSINE ACTIVITY

Phosphotyrosine activity was measured by 


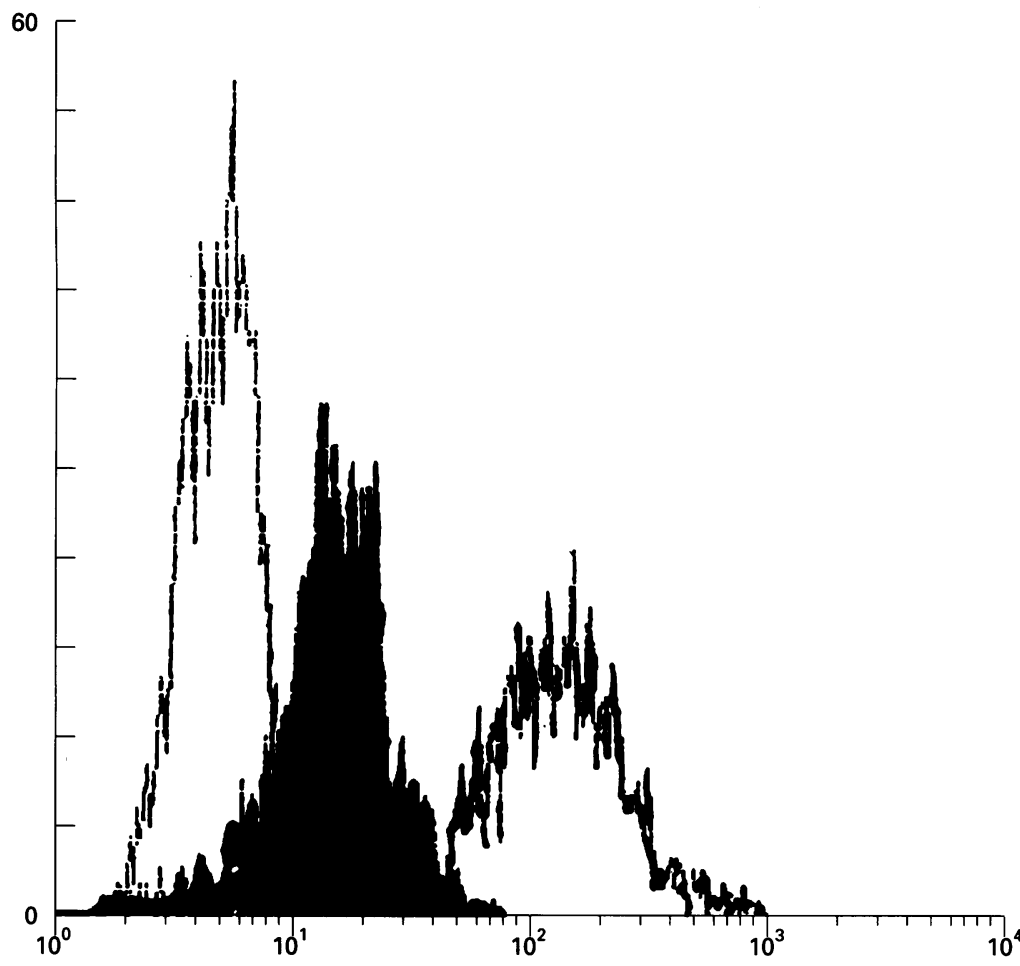

Figure 1: Tyrosine phosphorylation as measured by flow cytometry using anti-phosphotyrosine antibody in epithelial cells isolated after one hour incubation with EDTA/DTT. Histograms are gated on the CD3 negative population. The histogram on the far left represents the isotype specific control. Shaded histogram represents epithelial cells from a duodenal biopsy specimen preincubated in the absence of EGF and the far right histogram represents epithelial cells incubated with EGF. This causes a shift to the right indicative of tyrosine phosphorylation. Representative of three experiments.

indirect immunofluorescence and flow cytometry. The epithelial layer of the intestine was removed from the duodenal biopsy specimens by methods previously described. ${ }^{15}$ Briefly, specimens were incubated in $1 \mathrm{mM}$ EDTA and DTT in RPMI 1640 containing fetal calf serum. The samples were incubated with antiCD3 antibody directly conjugated to phycoerythrin (Becton Dickinson) and subsequently fixed with $2 \%$ paraformaldehyde. These cells were then permeabilised using $0.05 \%$ saponin in phosphate buffered saline (PBS). Henceforth all incubations and washes were carried out in $0.05 \%$ saponin/PBS. Antiphosphotyrosine antibody (Oncogene Sciences) or control antibody was then applied and incubated for 30 minutes. After 30 minutes of incubation, samples were washed and reincubated with a biotinylated affinity purified second antibody for 10 minutes. Samples were washed three times and then incubated with streptavidin fluorescein conjugate (Serotec) for 10 minutes. After two subsequent washes samples were then analysed by flow cytometry. Two colour cytofluorometric analysis was performed using the Becton-Dickinson FACSCAN with Lysis 2 software. In some experiments, samples were placed in 96 microtitre plates and incubated for four hours in the presence of epidermal growth factor $4 \mathrm{ng} / \mathrm{ml}$.

PHOSPHOTYROSINE ANTIBODY STAINING AND POSITION OF CELIS WITHIN CRYPTS

Specimens were incubated for sequential periods for 30 minutes, 60 minutes, 90 minutes, and two hours in the presence of EDTA/DTT with removal of the epithelial layer at each time point. A separate sample was treated identically and the biopsy specimen fragments fixed for routine histological tests. Phosphotyrosine staining was carried out as described above and samples read on flow cytometry. In addition, we performed staining for epithelial cell numbers using the Ber Ep-4 monoclonal antibody (Dakopatts) to confirm epithelial cell percentages at each of the four time points.

\section{PHOSPHOTYROSINE STAINING ON TISSUE SECTIONS}

Phosphotyrosine staining was performed according to manufacturer's instructions (Oncogene Sciences, Uniondale, New York). Tissue sections were deparaffinised in decreasing concentrations of xylene in ethanol before incubation in $1 \%$ hydrogen peroxide to quench endogenous peroxidase activity. They were then incubated in saponin $0.05 \%$ followed by washing in PBS followed by blocking in horse serum $(1 / 20)$ for 10 minutes. After washing, sections were incubated in primary or isotype control antibodies (Oncogene Sciences) in PBS-bovine serum albumin (1\%) for 60 minutes at room temperature after which they were washed three times in PBS. Sections were then incubated with biotinylated rabbit antimouse secondary antibody for 30 minutes. After washing with PBS sections were then incubated with $\mathrm{ABC}$ complex (streptavadinhorseradish peroxidase). Finally, sections were washed extensively in distilled water and $1 \%$ Triton-X 100 for 30 seconds before a final 15 minute incubation in diaminobenzidine solution before counterstaining with haematoxylin and eosin.

\section{Results}

PHOSPHOTYROSINE EXPRESSION - EFFECT OF EGF

As Figure 1 shows, tyrosine phosphorylation was easily detectable in epithelial cells isolated after one hour incubation with EDTA/DTT. Furthermore, the epithelial growth factor receptors on these cells are clearly functional in that incubation of specimens for four hours in the presence of EGF resulted in a significant increase in phosphorylation as measured by phophotyrosine antibody staining. These data suggest that epithelial cells isolated after one hour incubation with EDTA/DTT have a constitutive level of tyrosine kinase activity and furthermore that the EGF receptors on these cells are functioning as tyrosine kinases in increasing the amount of tyrosine phosphorylation in these cells.

PHOSPHOTYROSINE EXPRESSION WITH PROGRESSION THROUGH THE CRYPT Figure 2 shows parallel histograms of $\mathrm{CD} 3$ positive and $\mathrm{CD} 3$ negative cells taken at various time points of EDTA/DTT incuba- 

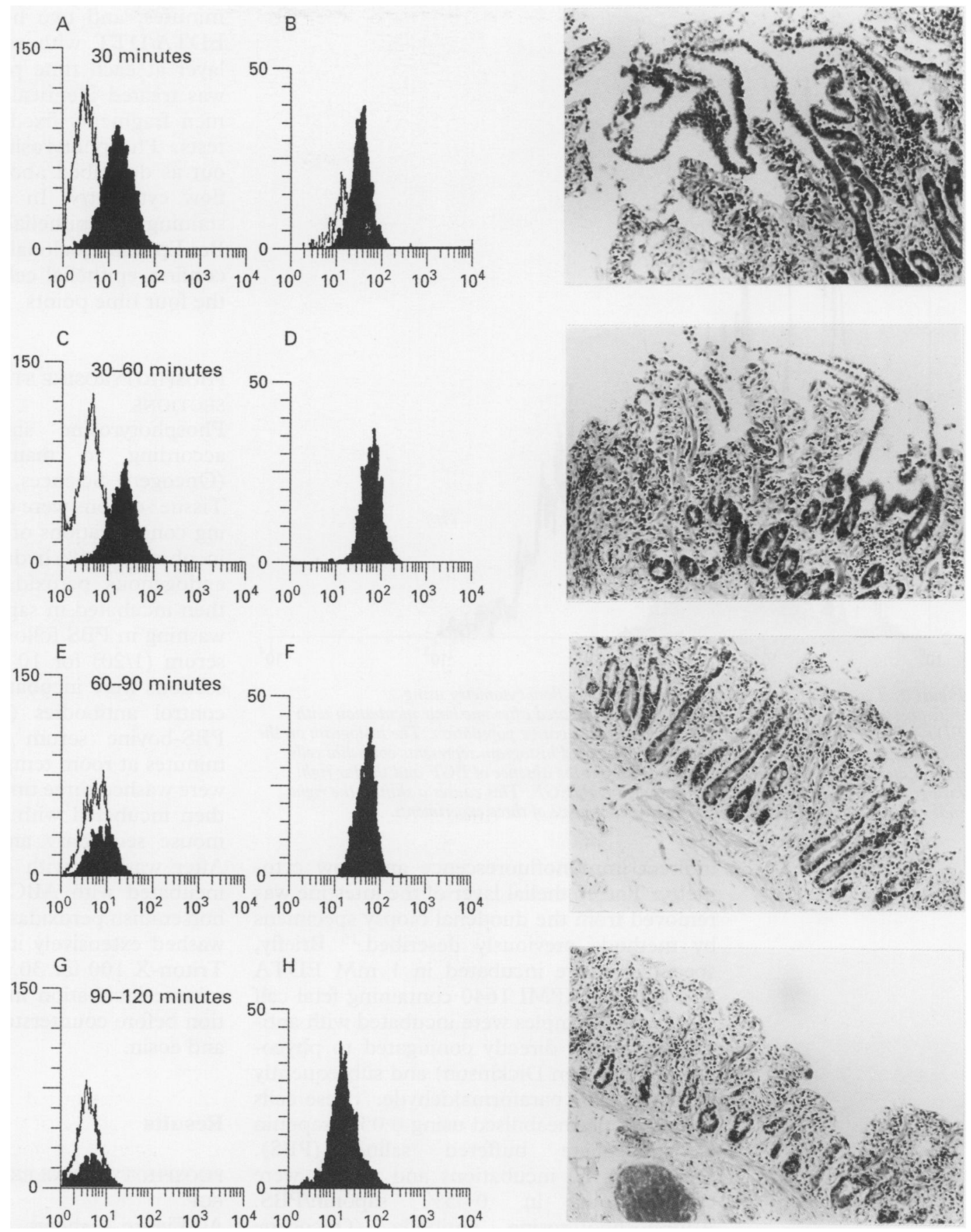

Figure 2: Flow cytometry profiles of phosphotyrosine expression in both $C D 3$ negative $(A, C, E, G)$ and $C D 3$ positive $B, D, F, H)$ cells isolated at 30 minutes, 30-60 minutes, 60-90 minutes, and 90-120 minutes. The open profile on the left $(A, C, E, G)$ represents results with an isotype specific control and the dark shaded region represents staining with anti-phosphotyrosine antibody. Background isotype control staining in the CD3 positive population overlaps the specific staining in $D, F, H$ and is hence not visible. Profiles on the right illustrate the fact that sequential incubation results in release of cells from deeper within the crypt. At 120 minutes only cells within the lower third of the crypt remain.

tion. The 30 minute incubation with EDTA/DTT removes surface enterocytes only from the villous tips. With longer incubations, it can be seen that cells are being taken from positions within the crypt at time points of 90 minutes and two hours. It is evident from Fig 2 $(\mathrm{A}, \mathrm{C}, \mathrm{E}, \mathrm{G})$ that tyrosine phosphorylation decreases with progression down the duodenal crypt. By contrast, tyrosine phosphorylation was low to absent throughout the crypt in intraepithelial lymphocytes (Fig 2B, D, F, H). The percentage of Ber Ep-4 cells in the suspension obtained at 30 minutes was $71 \%$. This did not show a significant decline with progression through the crypt as the percentage of
Ber Ep- 4 cells obtained at the two hour time point was $67 \%$.

\section{IMMUNOHISTOCHEMISTRY}

We also studied the tyrosine phosphorylation in patients with coeliac disease. In this condition there is an increase in epithelial proliferation in the duodenal crypts particularly in the middle third. We studied duodenal biopsy specimens obtained from both normal and coeliac disease patients by immunohistochemistry for phosphotyrosine activity. In normal subjects tyrosine phosphorylation is maximal on the villi with very little tyrosine phosphory- 

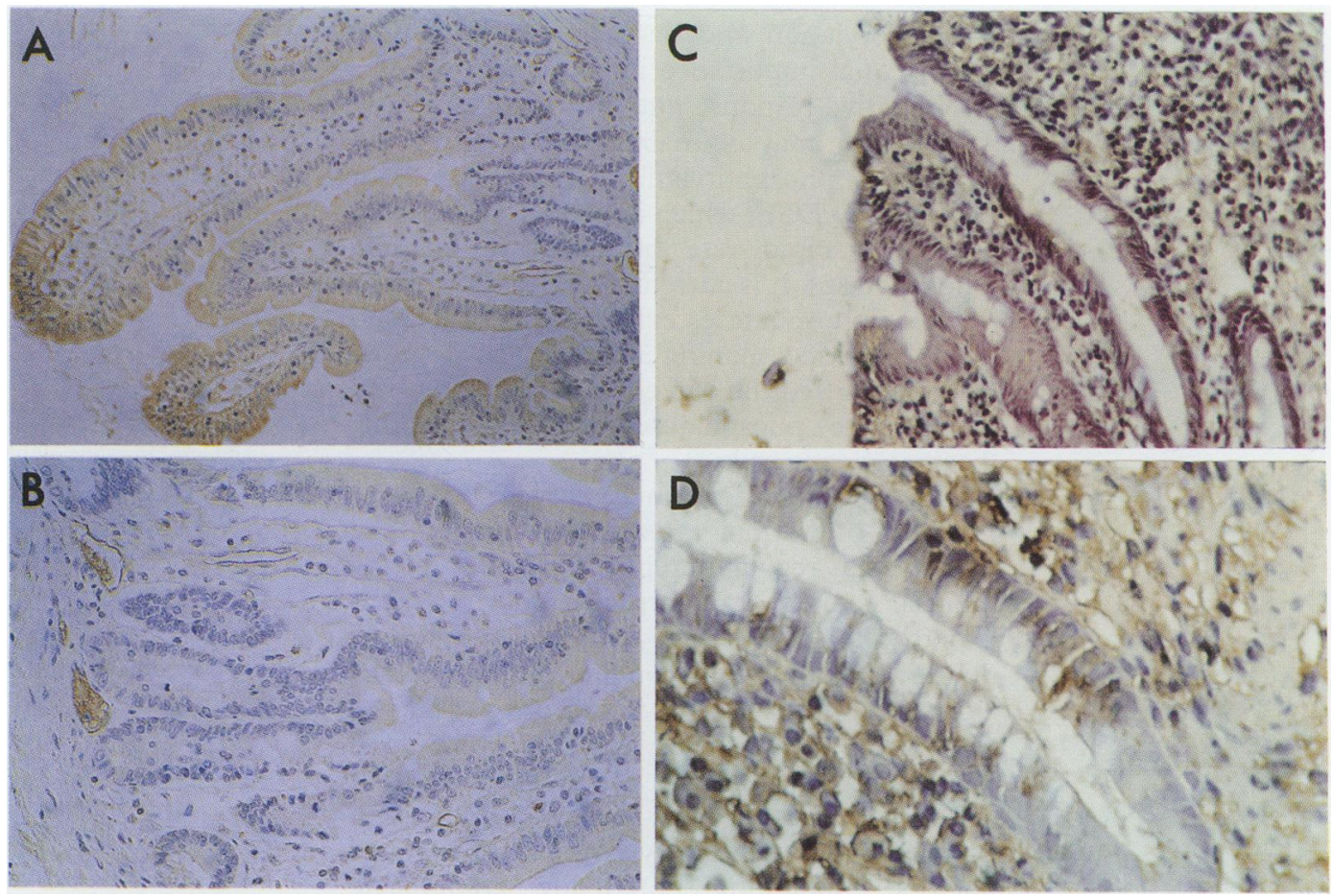

Figure 3: Immunohistochemistry of phosphotyrosine staining on normal $(A, B)$ and coeliac disease duodenum $(C, D)$ with magnification of $200(A, C)$ and $400(B, D)$. Positive staining is brown. The normal duodenum has evidence of phosphotyrosine staining on the villi but staining is reduced with progression into the crypts. In the coeliac duodenum phosphotyrosine expression is minimal on both surface and crypt even within the hyperproliferative middle third of the crypt. Note however, phosphotyrosine expression in both lamina propria and intraepithelial lymphocytes in the coeliac duodenum.

lation evident in the duodenal crypt (Fig 3A, $B)$. In the coeliac disease patients, there is minimal tyrosine phosphorylation detected either on the surface epithelium or in the crypts (Fig $3 \mathrm{C}, \mathrm{D})$. In some patients, tyrosine phosphorylation was evident on the surface epithelium. There is, however, clearly little or no tyrosine phosphorylation present in the coeliac crypt. By contrast it is clear that the lymphocytes within the coeliac crypt express significant levels of phosphorylated tyrosine suggesting that these activated lymphocytes are using tyrosine kinases in their pathways of activation.

\section{Discussion}

In this study we have developed a novel two colour flow cytometric method for the assay of tyrosine phosphorylation in endoscopically obtained duodenal epithelial cells. This assay has shown that tyrosine phosphorylation is present in epithelial cells from the villi and that this is functionally regulated by EGF. It has been recognised for many years, however, that the site of proliferation in the human duodenum is the middle third of the crypt. ${ }^{16}$ The percentage of cells in $\mathrm{S}$ phase in the middle third of the crypt ranges from $12 \%$ in normal subjects to $21 \%$ in coeliac disease patients. ${ }^{17}$ Virtually all crypt epithelial cells express proliferating cell nuclear antigen (unpublished data). Our data clearly show, using flow cytometry and immunohistochemistry, that levels of tyrosine phosphorylation are extremely low in crypt epithelial cells. Significantly, while levels of phosphorylation were high in the lamina propria lymphocytes of coeliac disease patients, crypt epithelial cell tyrosine kinase activity was virtually absent. In fact, the main cells staining for tyrosine phosphorylation in coeliac disease are the infiltrating intraepithelial lymphocytes. These data cast doubt on the thesis that EGF is the dominant growth factor for human duodenal crypt proliferation. These data are consistent, however, with previous findings that EGF may be secreted by a novel lineage induced by ulceration, which discharges at the villous tip ${ }^{10}$ and with the finding that transforming growth factor alpha, which shares the same receptor as EGF is distributed mainly on villous cells. ${ }^{18}$ These data suggest that the biological effects of these agents are located mainly in the nonproliferative villous epithelium and further suggest that tyrosine phosphatases, which cleave phosphate groups from tyrosine residues ${ }^{19} 20$ may be of critical importance in the regulation of crypt proliferation. Recently, a number of protein tyrosine phosphatases have been characterised and found to be of importance in the regulation of proliferation. Probably the best known of these is the CD45 molecule, which is expressed on lymphocytes. Deletion of the cytoplasmic domain in CD45, which has intrinsic tyrosine phosphatase activity results in the inability of $\mathrm{T}$ lymphocytes to proliferate in response to signals. ${ }^{21}$ The CD45 tyrosine phosphatase seems to be required for the coupling of $\mathrm{T}$ cell antigen receptor signals to the phosphoinositol second messenger signal and paradoxically may also participate in the rapid increase in tyrosine phosphorylation induced by activation of the $T$ cell receptor. ${ }^{22} 23$ In addition, another well characterised tyrosine phosphatase, LAR, is diffusely expressed on epithelial tissue ${ }^{24}$ and could be a candidate tyrosine phosphatase for participation in epithelial cell proliferation. 
Phosphorylation and dephosphorylation may be of equal importance in the induction of a proliferative response and it is possible that a steady state may be maintained with ongoing tyrosine phosphorylation mediated for example by EGF, which is being cleaved at an extremely rapid rate by excessive tyrosine phosphatases. It is currently unclear how many tyrosine phosphatases exist. Polymerase chain reaction based cloning methods have, however, permitted the detection of large numbers of tyrosine phosphatases in, for example, haematopoetic cells. ${ }^{25}$

Crypt proliferation is necessary for the maintenance of normal intestinal structure. The factors that regulate crypt proliferation in the normal subject are currently poorly understood. The novel lineage that results, however, in the secretion of EGF on the epithelial villous structure seems to be induced by mucosal ulceration. ${ }^{10}$ Increased crypt proliferation occurs in coeliac disease where it precedes flat mucosa. ${ }^{26}$ This increase in crypt proliferation is probably mediated by lymphocyte derived factors ${ }^{27}$ including potentially granulocyte macrophage-colony stimulating factor ${ }^{28}$ rather than EGF. Significantly, activated complement has been detected in Brunner's glands in coeliac disease suggesting possible dysfunction of this alternative source of EGF. ${ }^{29}$

In conclusion, we have shown that tyrosine phosphorylation in the human duodenum is at its lowest level at the site of maximal cellular proliferation. EGF does induce tyrosine phosphorylation detectable by flow cytometry in cultured human epithelial cells. These findings strongly suggest that epidermal growth factor is not the dominant factor for epithelial cell proliferation in the adult human duodenum. Secondly, if tyrosine kinases participate in the regulation of epithelial proliferation, then there must be a steady state situation in which there is a dominant effect of tyrosine phosphatases in the dephosphorylation of tyrosine residues on growth factor receptors in the intestine. None the less, we cannot exclude the possibility that EGF is a growth factor in neonatal development ${ }^{7}$ or after injury or ulceration. ${ }^{10} 30$ Finally, the development of a flow cytometric system for the study or tyrosine phosphorylation in endoscopically obtained duodenal epithelial cells could permit future studies on factors acting through tyrosine kinases of phosphatases in this otherwise comparatively inaccessible tissue site.

DK is a Wellcome Senior Fellow in Clinical Science. AL is supported by a grant from the Cancer Research Advancement Board.

This work was supported by a grant from the Wellcome Trust.

1 Ullrich A, Schlesinger J. Signal transduction by receptors with tyrosine kinase activity. Cell 1990; 61: 203-12.

2 Williams LT. Signal transduction by the platelet-derived growth factor receptor. Science 1989; 243: 1564-70.

3 Greenfield C, Hiles I, Waterfield MD, Federwisch W, Woolmer A, Blundell TL, et al. EGF binding induces a conformational change in the external domain of its receptor. $E M B O \mathcal{F} 1989 ;$ 8: $4115-24$.

4 Chen WS, Lazar CS, Poenie M, Tsien RY, Gill GN, Rosenfeld MG. Requirement for intrinsic protein tyrosine kinase in the immediate and late actions of the EGF receptor. Nature 1987; 328: 820-3.
5 Weaver LT, Walker WA. Epidermal growth factor and the developing human gut. Gastroenterology 1988: 94: 845-7.

6 Goodlad RA, Wilson TG, Lenton W, Wright NA, Gregory $\mathrm{H}$, McCullagh KG. Urogastrone-epidermal growth factor is trophic to the intestinal epithelium of parenterally fed rats. Experientiae 1985; 41: 1161-3.

7 Walker-Smith JA, Phillips AD, Walford N, Gregory $\mathrm{H}$, alker-Smith JA, Phillips AD, Walford N, Gregory $\mathrm{H}$,
Fitzgerald JD, MacCullagh $\mathrm{K}$, et al. Intravenous epidermal growth factor/urogastrone increases small intestinal cell proliferation in congenital microvillous atrophy [Letter]. Lancet 1985; ii: 1239-40.

8 Goodlad RA, Wilson TG, Lenton W, Wright NA, Gregory $\mathrm{H}$, McCullagh KG. Intravenous but not intragastric urogastrone-EGF is trophic to the intestinal epithelium of parenterally fed rats. Gut $1987 ; 28: 573-82$.

9 Polak PF, Goda T, Colony PC, Edmond J, Thornburg W, Kore M, et al. Effect of enterally fed EGF on the small and large intestine of the suckling rat. Regul Pept 1987; 17: and large

10 Wright NA, Pike C, Elia G. Induction of a novel epidermal growth factor-secreting cell lineage by mucosal ulceration in human gastrointestinal stem cells. Nature 1990; 343: 82-5.

11 Huhn RD, Posner MR, Rayter SI, Foulkes JG, Frackleton AR. Cell lines and peripheral blood leukocytes derived from individuals with chronic myelogenous leukaemia display virtually identical phosphotyrosyll proteins. Proc Natl Acad Sci USA 1987; 84: 4408-12.

12 Sengupta A, Liu WK, Yeung YG, Yeung DC, Frackelton $\mathrm{AR}$, Stanley ER. Identification and subcellular localization of proteins that are rapidly phosphorylated on tyrotion of proteins that are rapidly phosphorylated on tyro-
sine in response to colony-stimulating factor 1. Proc Natl sine in response to colony-stimulat
Acad Sci USA 1988; 85: 8062-6.

13 Ferris DK, Willette-Brown J, Ortaldo JR, Farrar WL. Interleukin 2 regulation of tyrosine kinase activity is mediated through the p70-75 beta subunit of the IL-2 receptor. f Immunol 1989; 143: 870-6.

14 Preis PN, Waldman FM, Frackleton AR, Saya H, Levin VA. Protein tyrosine kinase activity and pp60v-src expression in whole cells measured by flow cytometry. Cancer Res 1988; 48: 4633-8.

15 Madrigal L, Lynch S, Feighery C, Weir D, Kelleher D, O'Farrelly C. Flow cytometric analysis of surface major histocompatibility expression on human epithelial cells prepared from small intestinal biopsies. f Immunol prepared from small inte

16 Wright NA, Watson A, Morley A, Appleton D, Marks J. Cell kinetics in flat (avillous) mucosa of the human small intestine. Gut 1973; 14: 701-10.

17 McDevitt J, O'Farrelly C, Weir DG, Omary MB, Feighery C, Kelleher D. Proliferation-associated markers in the coeliac duodenum. Eur $\mathcal{f}$ Gastroenterol Hepatol 1994; 6: 223-8.

18 Thomas DM, Nasim MM, Gullick WJ, Alison MR. Immunoreactivity of transforming growth factor alpha in the normal adult gastrointestinal tract. Gut 1992; 33: $628-31$.

19 Hunter T. Protein-tyrosine phosphatases: the other side of the coin. Cell 1989; 58: 1013-6.

20 Peraldi P, Hauguel de-Mouzon S, Alengrin F, van Obberghen E. Dephosphorylation of human insulin-like growth factor 1 (IGF-1) receptors by membrane-associated tyrosine phosphatases. Biochem $\mathcal{F}$ 1992; 285: 71-8.

21 Trowbridge IS. CD45. A prototype for transmembrane protein tyrosine phosphatases. Fु Biol Chem 1991; 266: 23517-20.

22 Peyron JF, Verma S, deWaal-Malefyt R, Sancho J, Terhorst C, Spits H. The CD45 protein tyrosine phosphatase is required for the completion of the activation program leading to lymphokine production in the Jurkat human $\mathrm{T}$ cell line. Int Immunol 1991; 3: 1357-66.

23 Koretzky GA, Kohmetscher MA, Kadleck T, Weiss A. Restoration of $T$ cell receptor-mediated signal transducRestoration of T cell receptor-mediated signal transduc-
tion by transfection of CD $45 \mathrm{cDNA}$ into a CD45-deficient variant of the Jurkat T cell line. 7 Immunol 1992; cient variant of

24 Streuli M, Kreuger NX, Ariniello PD, Tang M, Munro JM, Blattler WA, et al. Expression of the receptor-associated protein tyrosine phosphatase LAR: proteolytic cleavage and shedding of the CAM-like extracellular domain. $E M B O \mathcal{F} 1992$; 11: 897-907.

25 Yi T, Cleveland JL, Ihle JN. Identification of novel protein tyrosine phosphatases of hematopoietic cells by polymerase chain reaction amplification. Blood 1991; 78: 2222-8.

26 March MN, Loft DE, Garner VG, Gordon D. Time/dose response of coeliac mucosae to graded oral challenges
with Frazer's fraction III of gliadin. Eur $\mathcal{f}$ Gastroenterol with Frazer's fraction III
Hepatol 1992; 4: 667-73.

27 MacDonald TT. The role of activated T lymphocytes in gastrointestinal disease. Clin Exp Allergy 1990; 20: 247-53.

28 Lowes JR, Priddle JD, Jewell DP. Production of epithelial cell growth factors by lamina propria mononuclear cells. Gut 1992; 33: 39-43.

29 Gallagher RB, Kelly CP, Neville S, Sheils O, Weir DG, Feighery CF. Complement activation within the coeliac small intestine is localised to Brunner's glands. Gut 1989; 30: $1568-78$.

30 Goodlad RA, Wright NA. Growth control factors in the gastroduodenal tract. Baillieres Clin Gastroenterol 1990; 4: 97-118. 